\title{
Phosphorylation-induced activation of tilapia nonspecific cytotoxic cells by serum cytokines
}

\author{
Jaime Ruiz, John H. Leary III, Liliana Jaso-Friedmann* \\ Department of Medical Microbiology and Parasitology, College of Veterinary Medicine, University of Georgia, Athens, \\ Georgia 30602-7386, USA
}

\begin{abstract}
Cytokines as soluble mediators of immunity are important in understanding immunological mechanisms against infectious organisms and during stress conditions. In the present study, the role of protein tyrosine phosphorylation is assessed in the activation of nonspecific cytotoxic cells (NCC) from tilapia Oreochromis niloticus by cytokine-like serum factors. NCC are the teleost equivalent of mammalian natural killer (NK) cells. In teleost fish, NCC are important mediators of innate immunity against bacterial and parasite insult and tumor growth. We have previously shown that exposure of tilapia (a tropical fish) to cold water temperatures ( 3 to $5 \mathrm{~min}$ at 5 to $10^{\circ} \mathrm{C}$ ) produces physiological stress responses characterized by immediate phenotypic and immunological changes. The serum obtained from stressed tilapia contains a 'stress activating serum factor' (SASF) which passively increases in vitro naïve NCC cytotoxicity 2- to 4 -fold over control levels. In an effort to identify the mechanisms of activation of cytotoxicity by SASF, the phosphorylation status of tyrosine residues in proteins from treated NCC was determined. NCC were incubated with heat-inactivated or untreated stress serum and Western blots of the cell lysates were probed with anti-phosphotyrosine monoclonal antibodies (mabs). The levels of tyrosine phosphorylation in several proteins of the SASF-activated NCC were higher than in control cells. Increased tyrosine phosphorylation was also induced by incubation of NCC in the presence of the tyrosine phosphatase inhibitor Na orthovanadate (vanadate). In every case, an increase in phosphorylation status shown by Western blotting was correlated with increases in cytotoxic activity of NCC against HL-60 target cells. The enzyme inhibitor Herbimycin A (HA) has been previously used to inhibit the activity of the src-family of tyrosine kinases. In the present study, a $4 \mathrm{~h}$ pretreatment of NCC with HA $(2 \mu \mathrm{M})$, followed by treatment with SASF blocked the activation of cytotoxicity produced by SASF. These results suggested that activation of NCC by cytokine-like factors is mediated through activation of the $s r c$ family of protein tyrosine kinases. Activation was associated with increased phosphorylation and higher cytotoxic effector functions.
\end{abstract}

KEY WORDS: NCC · Tilapia $\cdot$ Cytokines $\cdot$ Phosphorylation

Resale or republication not permitted without written consent of the publisher

\section{INTRODUCTION}

An important mechanism of innate immunity in tilapia Oreochromis niloticus is mediated by nonspecific cytotoxic cells (NCC), thought to be the teleost equivalent of mammalian natural killer (NK) cells (Jaso-Friedmann \& Evans 1999). NCC participate actively as the first barrier of defense in stress related

${ }^{*}$ Corresponding author. E-mail: ljaso@vet.uga.edu responses during adverse environmental conditions and following bacterial, viral or parasite infections (Jaso-Friedmann \& Evans 1999, Evans et al. 2000, JasoFriedmann et al. 2000). We have previously demonstrated that serum from temperature-stressed tilapia contains cytotoxicity activation factor(s) (i.e. stress activated serum factors, SASF) that amplify in vitro NCC activity isolated from peripheral blood of naive (nonstressed) fish (Jaso-Friedmann et al. 2000). Recognition of certain effector characteristics of SASF suggests the 
presence of cytokine-like soluble mediators in the serum of tilapia that are released as one of the immediate immunological responses to stress conditions.

Cytokines constitute extracellular signaling proteins or peptides that act as local mediators in cell-cell communication (Liles \& Van Voorhis 1995). Many of the cell-surface receptor proteins associated with these extracellular factors are activated by non-receptor protein tyrosine kinases (PTKs). These kinases phosphorylate various intracellular target proteins on tyrosine residues when the receptor binds its ligand (Miyahima et al. 1992, Mustelin \& Burn 1993, Schreurs et al. 1993). The kinases involved with these tyrosinekinase-associated receptors may belong to the SrC family of non-receptor PTKs. Proto-oncogenic kinases were first described as transforming proteins in Rous sarcoma virus transformed cells. At least 8 members of the src family of nonreceptor PTKs have been identified in mammals: $s r c, l y n, y e s, f g r, f y n, l c k, h c k$ and blk (Mustelin \& Burn 1993). Another family of non-receptor PTKs which constitutes an important component in cytokine activation of effector cells is the Janus family of enzymes (JAK1, JAK2 and Tyk2) (Argetsinger et al. 1993).

When the cytokine receptor binds its ligand on the surface of the cell, the tyrosine residues of the tyrosinekinase-associated receptors are phosphorylated by PTKs. This phosphorylation constitutes the first step of several downstream signaling events responsible for the cell activation. Various enzyme inhibitors of tyrosine kinases have been reported as useful tools for understanding the role of a specific family in signal transduction molecules involved in cell growth, differentiation or activation. The main function that this type of inhibitors has on NK cells and T cells is related to the inhibition of the cytotoxic activity associated with cellular phosphorylation events. Herbimycin A (HA) is one of the most common inhibitors used for the src family of kinases (Uehara et al. 1985, Uehara \& Fukazawa 1991, Li et al. 1995, Kalb et al. 1997, Sweeney et al. 1998).

As some tyrosine kinases are involved in cell activation, this could in turn be rapidly turned off by the opposite effect of a group of enzymes with tyrosine phosphatase activity. These tyrosine phosphatases induce dephosphorylation of the same type of receptor proteins (Walton \& Dixon 1993). Phosphatase inhibitors (zinc chloride, okadaic acid, etc.) have been previously used to demonstrate the role of phosphoproteins in signaling responses (Fisher et al. 1991). Sodium fluoride and sodium orthovanadate appear to have preferential binding specificities for serine and tyrosine residues, respectively (Alexander 1990, Hunke et al. 1995). In addition to being a broad-spectrum potent inhibitor of protein tyrosine phosphatases, sodium orthovanadate also inhibits $\mathrm{Na}+\mathrm{K}+$ ATPase, acid alkaline phosphatases, phosphofructokinase, and adenylate kinase (Hunke et al. 1995). Vanadate treatment has previously been shown to cause activation of catfish NCC cytotoxicity by prolonging the phosphorylation status of key tyrosine residues (Evans \& Jaso-Friedmann 1994).

In the present study we determined that tyrosine phosphorylation and dephosphorylation of proteins in tilapia NCC control the activation of effector functions by cytokine-like serum factors. Activation of NCC by SASF required an increase in protein tyrosine phosphorylation. The importance of the phosphorylation status on cytotoxicity was supported by data that showed that phosphatase inhibition (by treatment with sodium orthovanadate, $\mathrm{Na}_{3} \mathrm{VO}_{4}$ ) maintained high levels of tyrosine phosphorylation concomitantly with heightened cytotoxic activity. The involvement of the src family of protein kinases in tyrosine phosphorylation was demonstrated by the inability of SASF to activate cytotoxicity in the presence of HA. Further, we also show that both lck and fyn are expressed in tilapia NCC.

\section{MATERIALS AND METHODS}

Animals. Oreochromis niloticus (Tilapia nilotica) of both sexes were obtained from AmeriCulture (Animas, NM, USA). For 30 d or more before use, tilapia were maintained in flow-through 300 gallon (1100 l) fiberglass aquaria at a controlled water temperature $\left(25^{\circ} \mathrm{C}\right)$. Water quality monitoring included nitrite, ammonia nitrogen and chlorine determinations. The diet consisted of pelleted fish feed (Mazuri Choi, Purina Foods, St. Louis, MO, USA). Experimental fish were 85 to $100 \mathrm{~g}$.

Purification of NCC. Fish were bled from the caudal vein into heparinized syringes (1000 units $\mathrm{ml}^{-1}$ ). Cells were isolated from peripheral blood by standard techniques. Red cells were removed by 2 cycles of differential centrifugation at $650 \times g$ for $20 \mathrm{~min}$ on Histopaque 1077 (Sigma Chemicals, St. Louis, MO, USA). Cells remaining at the gradient interface cushion were collected, washed once and resuspended in complete RPMI 1640 (Cellgro, Media Tech, Washington, DC, USA). RPMI was adjusted to $280 \mathrm{mOsM}$ with $\mathrm{H}_{2} \mathrm{O}$ and supplemented with L-glutamine, sodium pyruvate, MEM vitamin solution, MEM amino acid solution, MEM nonessential amino acid solution (Cellgro, Media Tech) $50 \mathrm{mg} \mathrm{ml}^{-1}$ gentamicin (Schering-Plough Animal Health Corp., Kenilwork, NJ, USA) and 10\% heat inactivated fetal bovine serum (FBS) (Atlanta Biologicals, Atlanta, GA, USA).

Mab 5C6 or IgM isotype control was isolated from cell culture supernatants by ammonium sulfate precip- 
itation (50\% saturation) using standard techniques (Evans et al. 1988). This mab has specificity for a $32 \mathrm{kDa}$ membrane protein on NCC that functions as an antigen recognition and signalling molecule in catfish (JasoFriedmann et al. 1997), and tilapia (Jaso-Friedmann \& Evans 1999, Evans et al. 2000, Jaso-Friedmann et al. 2000). Purified NCC were 80 to $90 \%$ positive for mab $5 \mathrm{C} 6$ staining by flow cytometric analysis.

Stress activation. Stress-activated serum factors were generated as described (Jaso-Friedmann et al. 2000). Briefly, tilapia were immersed in cold water (5 to $15^{\circ} \mathrm{C}$, for 3 to $5 \mathrm{~min}$ ). Fish were immediately bled by caudal venipuncture and serum harvested using standard techniques. Collected sera were allowed to clot overnight at $4{ }^{\circ} \mathrm{C}$ in the dark and harvested by centrifugation (1000 $\times g$ for $30 \mathrm{~min})$.

Flow cytometry. Flow cytometry analysis was done in an EPICS XL-MCL 4 color SYSTEM IIR automated cell analysis system (Coulter Electronics Corp, Hialeah, FL, USA). Monoclonal antibody 5C6 was used to stain $2 \times 10^{5}$ cells prepared from peripheral blood $\left(60 \mathrm{~min} / 4^{\circ} \mathrm{C}\right)$. Cells were washed with cold PAB $\left(4^{\circ} \mathrm{C}_{i}\right.$ PBS $/ 0.1 \%$ azide $/ 1.0 \%$ bovine serum albumin). FITCconjugated anti-mouse IgM $(50 \mu \mathrm{l}$ of a 1:20 dilution; Sigma Chemicals) was added to each sample $\left(30 \mathrm{~min} / 4^{\circ} \mathrm{C}\right)$. Samples were washed twice and resuspended in cold $\mathrm{PAB}$ for analysis.

Cytotoxicity. Target cells for the chromium release cytotoxicity assays were human transformed HL-60 cells (ATCC CCL 240; human promyelocytic leukemia). Cell cultures were maintained in RPMI-1640 (Cellgro, Media Tech) containing $10 \%$ FBS. Target cells $\left(2 \times 10^{6}\right)$ were labeled with chromium-51 for $3 \mathrm{~h}$ at $37^{\circ} \mathrm{C}$, washed $3 \times$ with RPMI and resuspended at $1 \times 10^{5} \mathrm{cells} \mathrm{ml}^{-1}$. Equal volumes $(100 \mu \mathrm{ll})$ of labeled target cells and NCC were co-cultivated in 96-well round bottom microtiter plates for $16 \mathrm{~h}\left(28^{\circ} \mathrm{C}\right)$; supernatants were harvested and assayed for chromium-51 release. Percent of Specific Release (PSR) was calculated as follows: (test cpmspontaneous cpm/total cpm-spontaneous cpm) $\times 100$. Values expressed are means of triplicate samples.

Cell cycle analysis and determination of DNA hypoploidy. Camptothecin (CAM) (1 mM) (Sigma) was used to induce apoptosis and DNA hypoploidy in vitro. CAM, a DNA topoisomerase inhibitor (prevents DNA hybridization), is highly toxic to NCC cells in the S phase. Cell cycle analysis of purified NCC was performed to determine percentages of DNA hypoploidy. After different treatments and incubation times, $5 \times$ $10^{6} \mathrm{NCC}$ were treated with $1 \times$ NIM (Nuclear Isolation Medium) for $10 \mathrm{~min}$ at $4^{\circ} \mathrm{C}$ in the dark. NIM was prepared as follows: $0.5 \%$ PI, $0.01 \%$ Triton X-100 (Sigma) and $0.1 \%$ RNAse (Sigma) in PBS pH 7.3. The DNA content was analyzed by red flourescence. The percentage of NCC hypoploidy was determined by back- gating from PI fluorescence histograms into FL2 plots.

'In vitro' cell activation and Western blot analysis. Single cells suspensions of $5 \times 10^{7}$ tilapia NCC obtained from PBL were treated for $20 \mathrm{~min}$ with heat-inactivated SASF and with SASF. Cells were washed twice with cold PBS and then lysed for $30 \mathrm{~min}$ in lysis buffer (10 mM Tris $\mathrm{HCl}, 0.15 \mathrm{M} \mathrm{NaCl}, 1 \mathrm{mM}$ EDTA, $1 \mathrm{mM}$ EGTA, 1\% Triton-X100) freshly supplemented with $1 \mathrm{mM} \mathrm{Na}_{3} \mathrm{VO}_{4}, 1 \mathrm{mM}$ PMSF, $10 \mu \mathrm{g} \mathrm{ml}^{-1}$ aprotinin, leupeptin and pepstatin. After centrifugation at $4^{\circ} \mathrm{C}$ for $15 \mathrm{~min}$, supernatants were collected as cytoplasmic extracts. Samples were boiled for $5 \mathrm{~min}$ in loading buffer, separated in a $11.5 \%$ acrylamide gel and transferred to nitrocellulose membranes $(100 \mathrm{~V}$ for $60 \mathrm{~min}$ at $4^{\circ} \mathrm{C}$ ). Transfer efficiency was confirmed by total protein Ponceau S staining. All incubations from this point on were done with shaking at room temperature. Membranes were blocked for $1 \mathrm{~h}$ in TBST containing $5 \%$ non-fat milk (Jaso-Friedmann et al. 2000) and probed with anti-phosphotyrosine monoclonal antibodies (PY99, Santa Cruz Biotechnology, Santa Cruz, CA, USA). Membranes were washed 4 times (5 min each) with TBST/Tween before addition of the anti-mouse IgG conjugate and detection by chemiluminescence.

Two-dimensional gel electrophoresis. Two-dimensional gel electrophoresis was used as a combination of 2 high-resolution electrophoretic procedures. In the first dimension, solubilized samples were separated according to their isoelectric point (pI) in gels loaded in individual glass tubes. The tube gels were prepared with the following solution: $8.25 \mathrm{~g}$ urea, $6 \mathrm{ml}$ water, $2.0 \mathrm{ml}$ of $30 \%$ acrylamide $/ 1.8 \%$ bisacrylamide, $0.75 \mathrm{ml}$ ampholytes (pH 4 to 8 ) and $0.3 \mathrm{ml} \mathrm{NP}-40.10 \mu \mathrm{l}$ TEMED and $70 \mu \mathrm{l}$ of ammonium sulfate were added immediately before pouring to induce polymerizarion. The gels were pre-run for $15 \mathrm{~min}(200 \mathrm{~V}), 15 \mathrm{~min}(300 \mathrm{~V})$ and $30 \mathrm{~min}(400 \mathrm{~V})$ in anode (phosphoric acid $86 \%$ ) and cathode (sodium hydroxide $50 \%$ ) solutions. Samples were prepared (by 1:2 dilution in sample buffer: $2.85 \mathrm{~g}$ urea, $5 \mathrm{ml}$ water, 2-mercaptoethanol and $0.4 \mathrm{ml}$ ampholytes, $\mathrm{pH} 4$ to 8), loaded on the gels and run for $16.5 \mathrm{~h}$ at $700 \mathrm{~V}$. The tubes were frozen, the gels were separated and then applied to the top of an $11.5 \%$ acrylamide gel to be run at $626 \mathrm{~V}$. Gels were then transferred into nitrocellulose membranes at $30 \mathrm{~V}$ for $12 \mathrm{~h}$ min at $4^{\circ} \mathrm{C}$. Membranes were probed with antiphosphotyrosine monoclonal antibodies (PY-99, Santa Cruz Biotechnology) as described above.

Kinase and phosphatase inhibitors. NCC $\left(5 \times 10^{7}\right)$ received a $4 \mathrm{~h}$ pretreatment with $0.5,1$, and $2 \mu \mathrm{M}$ of HA (Calbiochem, La Jolla, CA, USA), followed by treatment with SASF. Cells were then lysed and tested by Western blot analysis as previously described. $\mathrm{Na}_{3} \mathrm{VO}_{4}$ was used as tyrosine phosphatase inhibitor. Single NCC suspensions of 50, 25, and $12.5 \mathrm{mM} \mathrm{Na}_{3} \mathrm{VO}_{4}$ were 
prepared to perform the cytotoxicity assays. At the same time, Western blotting was performed from cell lysates of $5 \times 10^{7} \mathrm{NCC}$ that were treated for $1 \mathrm{~min}$ with 5 $\mathrm{mM} \mathrm{Na}_{3} \mathrm{VO}_{4}$.

\section{RESULTS}

\section{SASF-activated NCC showed an increase in the tyrosine phosphorylation level of several proteins}

It was previously reported that NCC cytotoxicity is activated by SASF (Jaso-Friedmann et al. 2000). In order to study the mechanisms of activation by SASF, the phosphorylation status of tyrosine residues in NCC cellular proteins was measured. Lysates of activated and resting NCC were separated on $11.5 \%$ acrylamide gels, followed by Western blotting with an anti-tyrosine antibody. Results showed higher level of phosphorylation in cells treated with SASF compared to control cells (data not shown). The high degree of phosphorylation in activated NCC made it necessary to run samples on 2-dimensional (2-D) gels, in order to obtain better separation of individual protein species. As shown in Fig. 1, immunoblot analysis of proteins resolved by 2-D gel electrophoresis (11.5\% acrylamide) indicated a marked increase in the level of phosphorylation in several proteins of cell lysates that were treated with SASF compared to cells treated with heat-inactivated SASF.

The tyrosine phosphatase inhibitor sodium orthovanadate reduces tyrosine dephosphorylation while increasing cytotoxicity in NCC

It has been previously shown that catfish NCC cytotoxicity is increased in the presence of phosphatase inhibitors (Evans \& Jaso-Friedmann 1994). Similarly, the results shown now demonstrated the importance of tyrosine phosphorylation in cytotoxicity activation by serum cytokines. In order to gain a better understanding of the factors required for cytotoxic activation, experiments were next conducted to look at the effects of prolonged tyrosine phosphorylation on the killing capacity of NCC. Purified effector cells were incubated in the presence of different concentrations of a phosphatase inhibitor (sodium orthovanadate). NCC were subsequently washed and used in cytotoxicity assays against HL-60 target cells (Fig. 2). Results showed higher cytotoxic activity with increasing concentrations of vanadate (Fig. 2a). This dose response peaked at a concentration of $25 \mathrm{mM} \mathrm{Na}_{3} \mathrm{VO}_{4}$. The vanadate treatment on NCC also produced an increase in tyrosine phosphorylation status (shown in Fig. 2b) which paralleled the cytotoxicity activation (Fig. 2). The concentration of $\mathrm{Na}_{3} \mathrm{VO}_{4}$ required to induce higher detectable levels of phosphorylation in activated NCC by Western blots was lower ( $5 \mathrm{mM}$ ) than the concentration required to activate for maximum cytotoxic activity (Fig. 2a). This was probably attributable to a more sensitive detection system.

\section{$\mathrm{Na}_{3} \mathrm{VO}_{4}$ protected NCC from camptothecin-induced apoptosis}

Experiments were designed to identify a possible mechanism for the increase of cytotoxic activity by $\mathrm{Na}_{3} \mathrm{VO}_{4}$ in NCC. We had previously shown (Bishop et al. 2000) that incubation of NCC in SASF augments cytotoxicity by inhibiting the activation-induced program cell death occurring following contact with target cells. This protection from apoptosis produced by SASF causes in turn an increase in the NCC's recycling

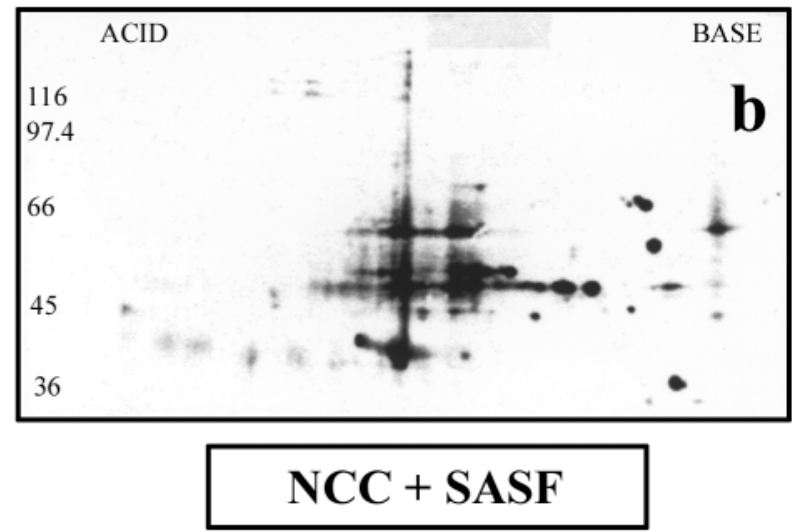

Fig. 1. Anti-phosphotyrosine Western blots from 2-D gels of NCC lysates. NCC from naïve tilapia were pre-treated with (a) heat inactivated SASF $\left(65^{\circ} \mathrm{C} / 15 \mathrm{~min}\right)$ and with (b) SASF. Cells were washed and lysates were loaded on 2-D gels. Western blots were of cell lysates were probed with anti-phosphotyrosine monoclonal antibodies (mabs) 

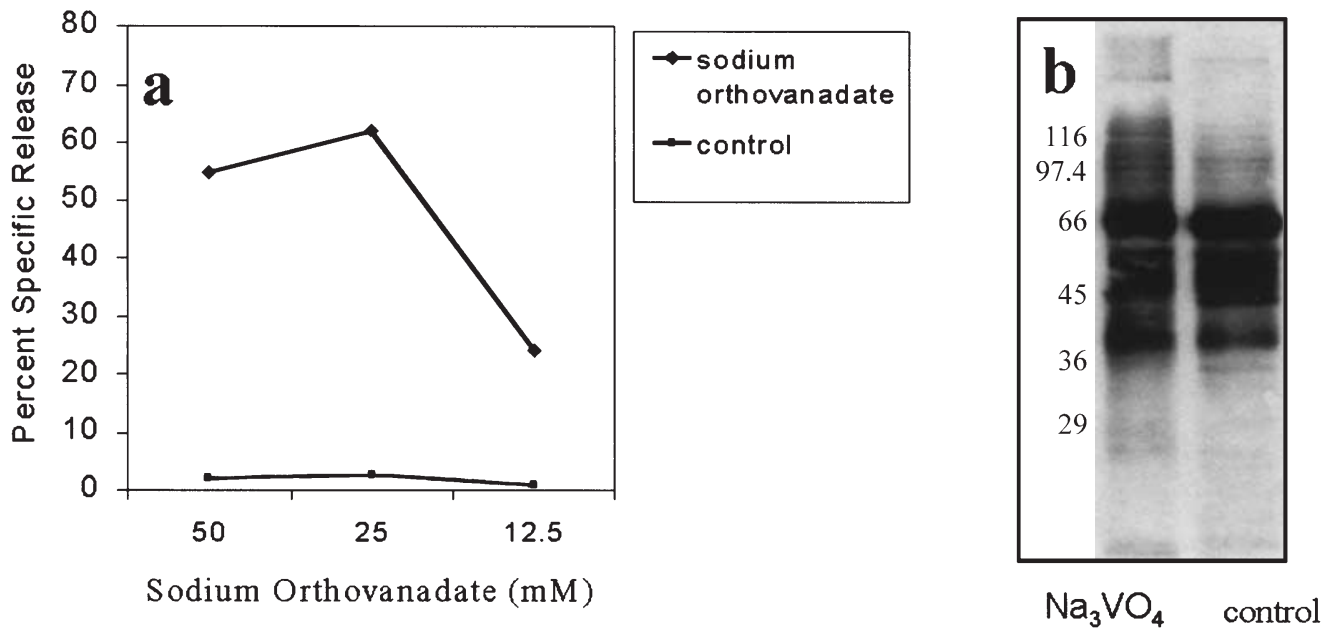

Fig. 2. Activation of NCC by sodium orthovanadate. Purified NCC from the peripheral blood of naïve tilapia were incubated with and without different concentrations of the tyrosine phosphatase inhibitor sodium orthovanadate $\left(\mathrm{Na}_{3} \mathrm{VO}_{4}\right)$. Cells were added to labeled HL-60 cells (E:T ratio 160:1). (a) Supernatants were harvested and radioactivity measured following $18 \mathrm{~h}$ co-cultivation. (b) At the same time, using the same groups of cells, Western blots from 1-D gels of cell lysates were probed with anti-phosphotyrosine monoclonal antibodies

capacity, leading to higher cytotoxicity. To study the possibility that this was the mechanism of activation by vanadate, apoptosis of NCC was induced by incubation with $1 \mathrm{mM}$ camptothecin. Fig. 3 shows a comparison of the cell cycle analysis of NCC treated with camptothecin (top, left panel) or in media alone (Fig. 3d). The diploid DNA peak is shown in Gate E, and any DNA to the left of that peak is indicative of smaller DNA fragments, i.e. hypoploidy (Gate $\mathrm{H}_{i}$ Gate $\mathrm{G}$ is the sum of $\mathrm{E}$ and H). NCC treated with camptothecin showed an increase in breakdown of diploid DNA (Gate H, Fig. 3a). This breakage is characteristic of camptothecin treatment due to the onset of apoptosis. This does not occur in untreated NCC (media-treated cells, Gate H, Fig. 3c). Camptothecin could not induce apoptosis in cells that had been previously exposed to SASF (Fig. 3b) or vanadate (top, right panel). Those histograms show that pretreatment of NCC with cytokines or vanadate protected the cells from the apoptotic effects of camptothecin treatment. There was little or no DNA present in the $\mathrm{H}$ gate in either of the 2 histograms, indicating similar results to those of control cells.

\section{Pretreatment of NCC with the tyrosine phosphorylation inhibitor $\mathrm{HA}$ reduces the activation of NCC by SASF}

The increase in tyrosine phosphorylation in NCC that leads to augmentation of cytotoxicity and protection from apoptosis could be due to activation of diverse families of protein kinases. In an effort to determine the involvement of the $s r c$ family of non-receptor tyrosine kinases, the activation of NCC by SASF in the presence of the PTK inhibitor HA was studied. Purified NCC were treated with HA followed by treatment with SASF. In Fig. 4, treatment of NCC with 1 to $2 \mu \mathrm{M}$ HA reduced the level of killing of target cells back to control levels (NCC treated with heat inactivated cytokines). The results also correlated with a decrease in the phosphorylation levels in the anti-phosphotyrosine Western blots from 1-D gels of NCC lysates (Fig. 4b). A low concentration of HA $(0.5 \mu \mathrm{M})$ had little effect on the phosphorylation status or on the cytotoxic activity of NCC. At higher HA concentrations phosphorylation, as well as cytotoxicity, were both inhibited. These results suggest that the increase in the killing capacity of NCC following treatment with serun cytokines required the activation of the $s r c$ family of protein kinases.

\section{Activated and resting NCC constitutively express lck and fyn}

It is not known whether tilapia NCC express srCfamily of protein tyrosine kinases. To further investigate if these enzymes could be the targets of the HA inhibition, single suspensions of $5 \times 10^{7} \mathrm{NCC}$ were treated for $20 \mathrm{~min}$ with SASF. Western blots of the resting or activated cell lysates were performed using policlonal antibodies against human lck and fyn. These antibodies were chosen because of their wide species crossreactivity as marketed by the manufacterer. Both lck (Fig. 5) and fyn (data not shown) were constitutively expressed in cell lysates obtained from control and SASF-treated NCC. Furthermore, phosphotyro- 


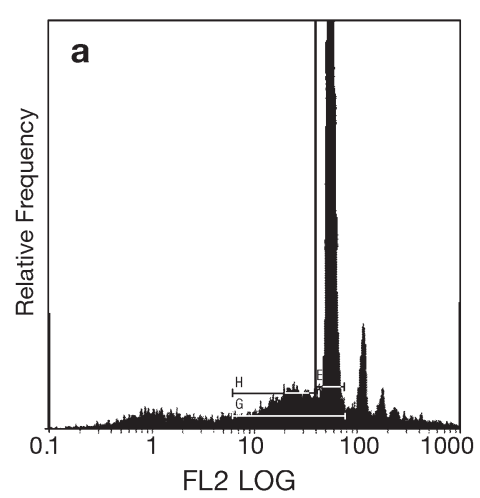

Camptothecin $1 \mathrm{mM}$ DNA hypoploidy $=22.2 \%$

Camptothecin $1 \mathrm{mM}+$ SASF $4 \mathrm{~h}$ DNA hypoploidy $=1.99 \%$

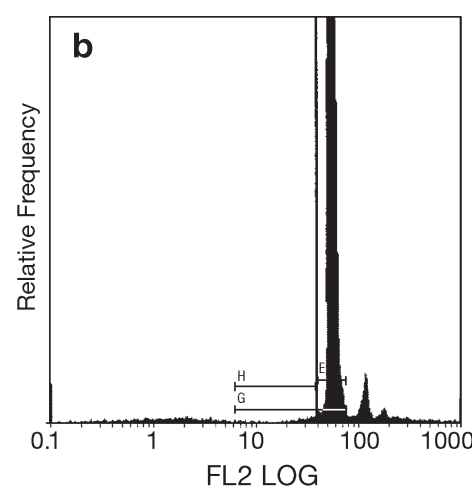

Camptothecin $1 \mathrm{mM}+$ Vanadate $50 \mathrm{Mm}$ DNA hypoploidy $=1.96 \%$

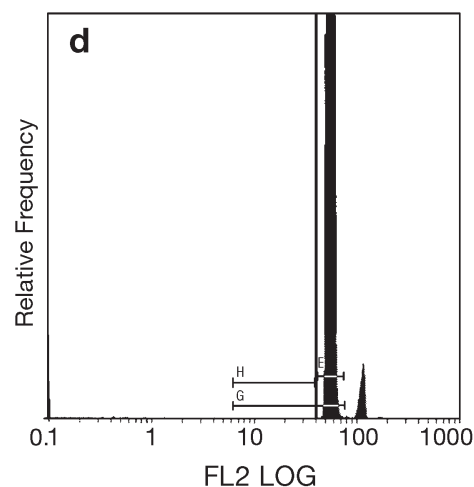

Media Control DNA hypoploidy $=0.14 \%$
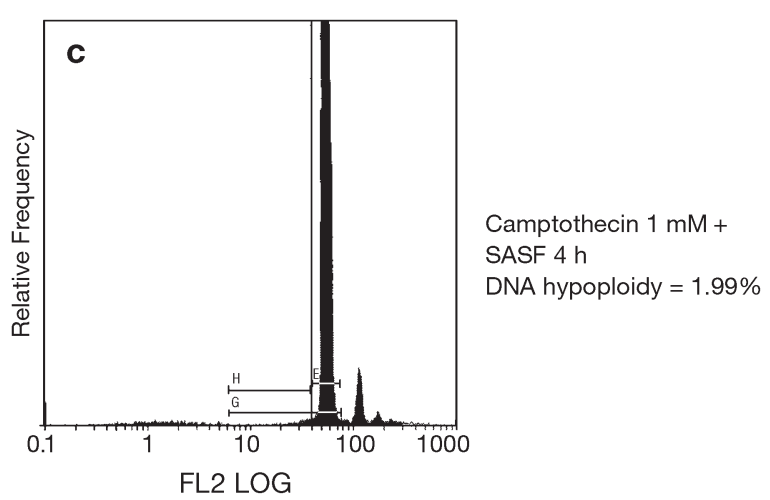

Fig. 3. Protective effects of increased phosphorylation on apoptosis of NCC. Purified NCC $\left(10^{6}\right)$ isolated from peripheral blood of naïve tilapia were pre-incubated for $4 \mathrm{~h}$ with SASF and with sodium orthovanadate. Pretreated NCC were then incubated with camptothecin $(1 \mathrm{mM}$ ) for $12 \mathrm{~h}$ (b and c). (a) Positive control. NCC treated with camptothecin. (b) Sodium orthovanadate-treated NCC were incubated in the presence of Camptothecin. (c) SASF-treated NCC were incubated in the presence of camptothecin. Gate E includes $2 \mathrm{~N}$ (diploid DNA) and Gate $\mathrm{H}$ is the DNA that is smaller than 2N (denoting hypoploidy). (d) Media control

sine Western blots of the kinases showed that activation did not increase the net phophorylation status of these enzymes (data not shown). These results are in agreement with published reports of the activation of the mammalian family of $s r c$ tyrosine kinases. Furthermore, the molecular weight of the teleost enzymes was comparable to that of the mammalian homologue (positive control lane).
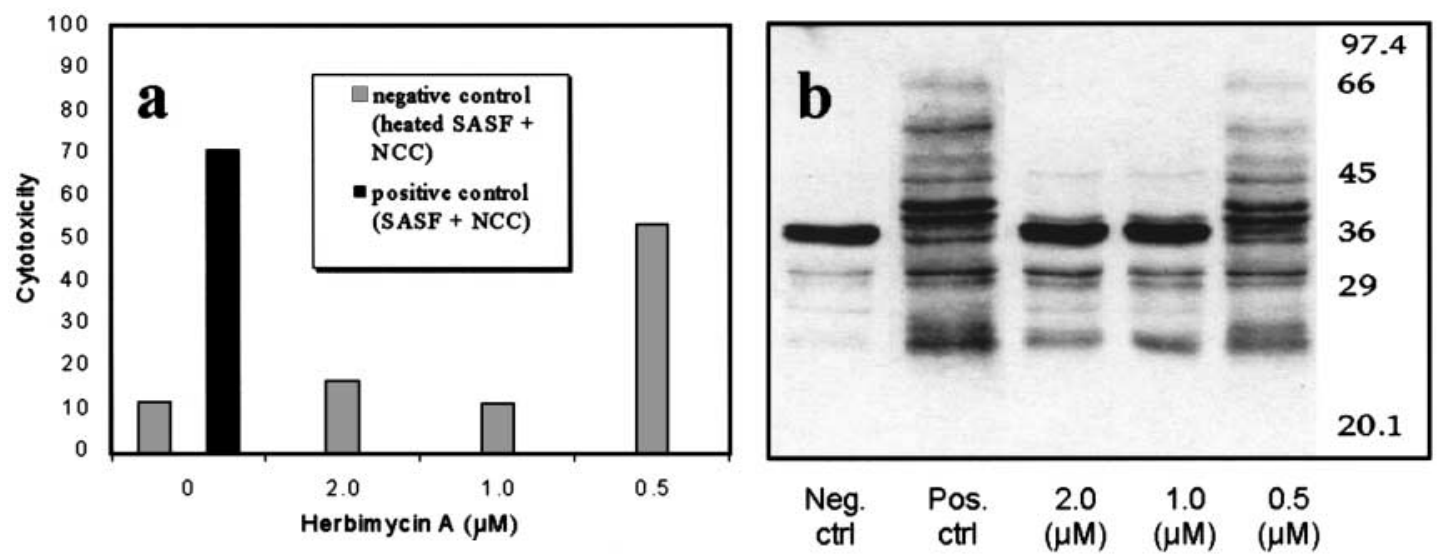

Fig. 4. HA inhibits the activation of NCC by SASF. Purified NCC from the peripheral blood of naïve tilapia were pre-incubated for $4 \mathrm{~h}$ with and without different concentrations of HA. Cells were washed and treated with SASF for $4 \mathrm{~h}$. Cells treated with heatinactivated SASF $\left(65^{\circ} \mathrm{C} / 15 \mathrm{~min}\right)$ were used as a negative control (ctrl). Finally, cells were washed and added to labeled HL-60 cells (E:T ratio 160:1). (a) Supernatants were harvested and radioactivity measured following $18 \mathrm{~h}$ cocultivation. (b) At the same time, the same cells were lysed and used for Western blots from 1-D gels, probed with anti-phosphotyrosine monoclonal antibodies 


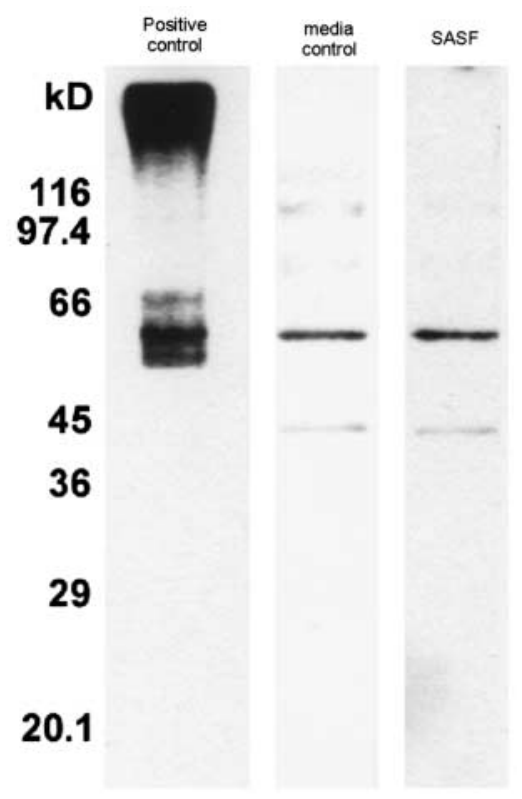

Fig. 5. lck is constitutively expressed in both naïve and activated NCC. Freshly isolated NCC $\left(5 \times 10^{6}\right)$ from peripheral blood of naïve tilapia were resuspended in RPMI followed by incubation in the presence and absence of SASF. NCC were then washed twice with cold PBS and lysed for $30 \mathrm{~min}$ in Triton-X100 lysis buffer. After centrifugation at $4^{\circ} \mathrm{C}$ for $15 \mathrm{~min}$, supernatants were collected as cytoplasmic extracts. Samples were heated with $4 \times$ loading buffer, separated in a $11.5 \%$ acrylamide gel and transferred to membranes for probing with anti-lck polyclonal antibodies (1:2000). Lane A: positive control of mammalian lck provided with the antibody. Lane B: NCC treated with media alone; Lane C: NCC incubated in the presence of SASF

\section{DISCUSSION}

Although the importance of lymphokines in natural and adquired immune responses is without question, very few cytokines have been sequenced to date in lower vertebrates (Secombes et al. 1998). For this and other reasons (lack of phenotyping reagents), very little is known about the specific molecular mechanisms of activation of fish lymphocytes during the typical immune response to viral and bacterial infections, parasite infestations and stress conditions. Reversible protein phosphorylation is the predominant strategy used to control the metabolic activity of proteins in eukaryotic cells (Johnson \& Barford 1993). Thus, phosphorylation and dephosphorylation reactions are essential in signal transduction events that control several cellular processes (Cohen 1989). Target cellular proteins are phosphorylated at specific serine, threonine or tyrosine residues by protein kinases and the phosphate group is then removed by the action of specific protein phosphatases (Alexander 1990). We have presented data showing evidence of downstream sig- naling events that occur in tilapia NCC following activation by cytokine-like factors. It is clear that interleukins can induce different cellular responses such as lymphocyte activation, growth and differentiation (Arai et al. 1990). A complex signaling system in which protein phosphorylation by nonreceptor PTKs appears to be critical (Arai et al. 1990, Taniguchi 1995) mediates such diverse responses. This is the first report showing how the addition and removal of phosphate groups from key tilapia NCC proteins affects effector functions. In particular, phosphorylation was shown to be indispensable in the activation of cytotoxic activity of tilapia NCC induced by serum cytokine-like factors.

The tyrosine phosphatase specific inhibitor sodium orthovanadate was shown to be an important immunomodulator of nonspecific cytotoxic cell activity in tilapia NCC. Similar results were reported with NCC isolated from channel catfish Ictalurus punctatus (Evans \& Jaso-Friedmann 1994). In both cases, this immunomodulation was a signaling event occurring at the level of an individual NCC. In addition, sodium orthovanadate showed protective effects against camptothecin-induced apoptosis of NCC. Although the role of tyrosine phosphorylation in cell growth and differentiation has been widely studied, very little is known about the role of phosphorylation in the regulation of programmed cell death (Yang et al. 1996, Kuli et al. 1997, Ueno et al. 1997, Lifshitz et al. 1998). Apoptosis plays important physiological roles not only in immune cells but in many other tissues.

One model that may confirm the regulation of signal transduction responses by phosphatases on NCC are studies related to the mechanisms of how the leukocyte common antigen CD45 participates in NK and T cell activation processes. It has been demonstrated that in rat NK cells CD45 regulates the inhibitory signal pathway after self MHC class I recognition. This event occurs apparently by dephosphorylation of certain cellular proteins (Giezeman-Smits et al. 1999). Additionally, biochemical analyses and immunofluorescence studies have shown that the tyrosine kinase associated with CD45 in NK cells is p56 $6^{\text {lck }}$ and that cross-linking of CD45 results in the activation of $\mathrm{p} 56^{\text {lck }}$ (Xu \& Chong 1995). Thus, CD45 may regulate p56 ${ }^{\text {lck }}$ kinase, which initiates the cascade of intracellular tyrosine phosphorylation events that lead to the transcription and secretion of cytokines such as IFN-gamma (Shen et al. 1995, Xu \& Chong 1995).

CD45 also plays an important role in T cell activation mechanisms by binding p56 ${ }^{\text {lck }}$ (Sieh et al. 1993, Lee et al. 1996, D'Oro \& Ashwell 1999, Gervais \& Veillette 1997, Pingel et al. 1999) and p59 $9^{\text {fyn }}$ as substrates (Hurley et al. 1993, Imbert et al. 1996). It has also been demonstrated how the stimulation of the T-cell antigen receptor-CD3 complex signaling pathway by pervana- 
date is mediated by inhibition of CD45 (Imbert et al. 1996). In addition, CD45-dependent events such as tyrosine phosphorylation of Shc (Ghosh \& Miller 1995), major histocompatibility class II-mediated signal transduction (Greer et al. 1998), and the stimulation of the T-cell antigen receptor-CD3 (Imbert et al. 1996) complex signaling pathway also involve the activation of the tyrosine kinases lck and fyn. Although we do not know if CD45 is expressed in tilapia NCC, these data, combined with the fact that $l c k$ and $f y n$ were found constitutively expressed on tilapia NCC, confirm our hypothesis that phosphatases inhibited by vanadate are directly associated with cytotoxicity.

The relationship between the inhibition of tyrosine kinase activity by HA and the inactivation of cytolysis in NK cells and CD3-large granular lymphocytes has been demonstrated in both natural cytotoxicity and antibody-dependent cellular cytotoxicity (O'Shea et al. 1992, Murakami et al 1998). The present report suggests that PTKs play an important role in the positive regulation of NCC activated by SASF. The inhibition occurred when NCC were treated with HA concentrations between 1.0 and $2.0 \mu \mathrm{M}$ (Fig. 4).

From the data presented above, it appears that factors with cytokine bioactivity play an important role in coordinating NCC responses of fish as in other vertebrates. Those factors appear within minutes in the serum of stressed fish in response to external conditions such as cold water stress or infectious diseases. The activation of NCC cells by serum cytokines is phosphorylation-induced; in addition, the signal transduction events that regulate the NCC activity are probably associated with the src family of PTKs. Furthermore, activation of killing may be related to the protection of NCC from activation-induced program cell death that occurs following target cell contact (Bishop et al. 2000). Future studies will be directed towards the identification of other second messengers that control lytic processes and killing kinetics of NCC.

\section{LITERATURE CITED}

Alexander DL (1990) The role of phosphatase in signal transduction. New Biol 2:1049-1062

Arai KI, Lee F, Miyajima A, Miyatake S, Arai N, Yokota T. (1990) Cytokines: coordinators of immune and inflammatory responses. Annu Rev Biochem 59:783-836

Argetsinger LS, Campbell GS, Yang X, Witthuhn BA, Silvennoinen O, Ihle JN, Carter-Su C (1993) Identification of JAK 2 as a growth hormone receptor-associated tyrosin kinase. Cell 74(2):237-244

Bishop GR, Jaso-Friedmann L, Evans DL (2000) Activation induced program cell death of nonspecific cytotoxic cells and inhibition by apoptosis regulatory factors. Cellular Immunol 199(2):126-137

Cohen P (1989) The structure and regulation of protein phosphatases. Annu Rev Biochem 58:453-508
D'Oro U, Ashwell JD (1999) The CD45 tyrosine phosphatase is an inhibitor of Lck activity in thymocytes. J Immunol 162(4):1879-1883

Evans D, Jaso-Friedmann L (1994) Role of protein phosphatases in the regulation of nonspecific cytotoxic cell activity. Dev Comp Immunol 18(2):137-146

Evans DL, Jaso-Friedmann L, Smith EE Jr, St John A, Koren HS, Harris DT (1988) Identification of a putative antigen receptor on fish nonspecific cytotoxic cells with monoclonal antibodies. J Immunol 141(1):324-332

Evans DL, Taylor S, Leary J, Bishop GR, Jaso-Friedmann L (2000) In vivo activation of tilapia nonspecific cytotoxic cells by Streptococcus iniae and duplication with apoptosis regulatory factor(s). Fish Shellfish Immunol 10(5):419-434

Fisher EH, Charbonneau H, Tonks NK (1991) Protein tyrosine phosphates: a diverse family of intracellular and transmembrane enzymes. Science 253(5018):401-406

Gervais FG, Veillette A (1997) Reconstitution of interactions between protein-tyrosine phosphatase CD45 and tyrosine-protein p56(lck) in nonlymphoid cells. J Biol Chem 272(19):12754-12761

Ghosh J, Miller RA (1995) Rapid tyrosine phosphorylation of Grb2 and Shc in T cells exposed to anti-CD3, and CD4, and anti-CD45 stimuli: differential effects of aging. Mech Ageing Dev 80(3):171-187

Giezeman-Smits KM, Gorter A, van Vlierberghe RL, v Eendenburg JD, Eggermont AM, Fleuren GJ, Kuppen PJ (1999) The regulatory role of CD45 on rat NK cells in target cell lysis. J Immunol 163(1):71-76

Greer SF, Lin J, Clarke CH, Justement LB (1998) Major histocompatibility class II-mediated signal transduction is regulated by the protein-tyrosine phosphatase CD45. J Biol Chem 273(19):11970-11979

Hunke S, Dose S, Schneider E (1995) Vanadate and fafilomycin A1 are potent inhibitors of the ATPase activity of the reconstituted bacterial ATP-binding cassette transporter for maltose (MalFGK2). Biochem Biophys Res Commun 216(2):589-594

Hurley TR, Hyman R, Sefton BM (1993) Differential effects of expression of the CD45 tyrosine protein phosphatase on the tyrosine phosphorylation of the lck, fyn, and c-src tyrosine protein kinases. Mol Cell Biol 13(3):1651-1656

Imbert V, Farahifar D, Auberger P, Mary D, Rossi B, Peyron J (1996) Stimulation of the T-cell antigen receptor-CD3 complex signalling pathway by the tyrosine phosphatase inhibitor pervanadate is mediated by inhibition of CD45: evidence for two interconnected Lck/Fyn-or zap-70dependent signalling pathways. J Inflamm 46(2):65-67

Jaso-Friedmann L, Evans D (1999) Mechanisms of Cellular cytotoxic innate resistance in Tilapia (Oreochromis niloticus). Dev Comp Immunol 23(1):27-35

Jaso-Friedmann L, Leary JH III, Evans DL (1997) NCCRP-1: a novel receptor protein sequenced from teleost nonspecific cytotoxic cells. Mol Immunol 34:955-965

Jaso-Friedmann L, Ruiz J, Bishop GR, Evans DL (2000) Regulation of innate immunity in Tilapia: activation of nonspecific cytotoxic cells by cytokine-like factors. Dev Comp Immunol 24(1):25-36

Johnson LN, Barford D (1993) The effects of phosphorylation on the structure and function of proteins. Annu Rev Biophys Biomol Struct 22:199-232

Kalb TH, Tio XY, Mayer L (1997) Human airway epithelial cells stimulate T-lymphocyte lck and fyn tyrosine kinase. Am J Respir Cell Mol Biol 17(5):561-570

Kuli GA, Klippel A, Weber MJ (1997) Antiapototic signaling by the insulin-like growth factor I receptor, phosphatidylinositol 3-kinase, and Akt. Mol Cell Biol 17:1595-1606 
Lee JM, Fournel M, Veillete A, Branton PE (1996) Association of CD45 with Lck and components of the Ras signalling pathway in pervanadate-treated mouse T-cell lines. Oncogene 12(2):253-263

Li Y, Yio XY, Mayer L (1995) Human intestinal epithelial cellinduced $\mathrm{CD}^{+} \mathrm{T}$ Cell Activation is mediated through CD8 and the activation of CD8-associated p56 $6^{\text {lck }}$. Exp Med 182(4):1079-1088

Lifshitz S, Schwartz B, Polak-Charcon S, Benharroch D, Prinsloo I, Lamprecht SA (1998) Extensive apoptotic death of rat colonic cells deprived of crypt habitat. J Cell Physiol $177: 377-386$

Liles, WC, Van Voorhis WC (1995) Nomenclature and biologic significance of cytokines involved in inflammation and the host immune response. J Infect Dis 172(6): $1573-1580$

Miyajima A, Hara T, Kitamura T (1992) Common subunits of cytokine receptors and the functional redundancy of cytokines. Trends Biochem Sci 17(10):378-382

Murakami Y, Fukazawa H, Mizuno S, Uehara Y (1998) Effect of herbimycin $\mathrm{A}$ on tyrosine kinase receptors and platelet derived growth factor (PDGF)-induced signal transduction. Biol Pharm Bull 21(10):1030-1035

Mustelin T, Burn P (1993) Regulation of src family tyrosine kinases in lymphocytes. Trends Biochem Sci 18(6):215-220

O'Shea JJ, McVicar DW, Kuhns DB, Ortaldo JR (1992) A role for protein tyrosine kinase activity in natural cytotoxicity as well as antibody-dependentcellular cytotoxicity. J Immunol 148(8):2497-2502

Pingel S, Baker M, Turner M, Holmes N, Alexander DR (1999) The CD45 tyrosine phosphatase regulates CD3-induced signal transduction and $\mathrm{T}$ cell development in recombinase-deficient mice: restoration of pre-TCR function by active p56(lck). Eur J Imunol 29(8):2376-2384

Schreurs J, Gorman DM, Mayajima A (1993) Cytokine receptors: a new superfamily of receptors. Int Rev Cytol 137B: $121-155$

Editorial responsibility: Donald Evans,

Athens, Georgia, USA
Secombes C, Zou J, Daniels G, Cunningham C, Koussounadis A, Kemp G (1998) Rainbow trout cytokine and cytokine receptor genes. Immunol Rev 166:333-340

Shen F, Xu XL, Graf LH, Chong AS (1995) CD45-cross-linking stimulates IFN-gamma production in NK cells. J Immunol 154(2):644-652

Sieh M, Bolen JB, Weiss A (1993) CD45 specifically modulates binding of Lck to a phosphopeptide encompassing the negative regulatory tyrosine of Lck. EMBO J 12(1):315-321

Sweeney JF, Nguyen PK, Omann GM, DB Hinshaw (1998) Lipopolysaccharide protects polymorphonuclear leukocytes from apoptosis via tyrosine phosphorylation-dependent signal transduction pathways. J Surg Res 74(1):64-70

Taniguchi T (1995) Cytokine signaling through nonreceptor protein tyrosine kinases. Science 268(5208):251-255

Uehara Y, Fukazawa H (1991) Use and selectivity of Herbimycin A as inhibitor of protein-tyrosine kinases. Methods Enzymol 201:370-379

Uehara Y, Hori M, Takeuchi T, Umezawa H (1985) Screening of agents which convert 'transformed morphology' of Rous sarcoma virus-infected rat kidney cells to 'normal morphology': identification of an active agent as herbimycin nd its inhibition of intracellular src kinase. Jpn J Cancer Res 76(8):672-675

Ueno H, Honda H, Nakamoto T, Yamagata T, Sasaki K, Miyagawa K, Mitani K, Yazaki Y, Hirai H (1997) The phosphatidylinositol 3-kinase pathway is required for the survival signal of leukocyte tyrosine kinase. Oncogene 14: 3067-3072

Walton KM, Dixon JE (1993) Protein tyrosine phosphates. Annu Rev Biochem 62:101-120

Xu X, Chong AS (1995) Cross-linking of CD45 on NK cells stimulates p561ck-mediated tyrosine phosphorylation and IFN-gamma production. J Immunol 155(11):5241-5248

Yang C, Chang J, Gorospe M, Passaniti A (1996) Protein tyrosine phosphatase regulation of endothelial cell apoptosis and differentiation. Cell Growth Differ 7:161-171

Submitted: February 5, 2001; Accepted: March 5, 2001

Proofs received from author(s): August 10, 2001 